P-ISSN: 2085-2541, E-ISSN: 2715-7865

Volume 13, Nomor 1, Juni 2021

https://ejournal.staindirundeng.ac.id/index.php/Tasyri

\title{
ONTOLOGI RIBA DALAM HADIS \\ (Kajian Tematik Hadis Ahkam)
}

\author{
Edy Saputra \\ STAIN Tengku Dirundeng Meulaboh \\ edysaputra@staindirundeng.ac.id
}

\begin{abstract}
Abstrak
Artikel ini memuat kajian tematik hadis ahkam tentang ontologi riba. Kajian ini termasuk katagori penelitian kepustakaan. Metode kajian yang digunakan adalah deskriftif analitis. Data primer dalam kajian ini berasal dari sembilan kitab hadis primer, yaitu Al-Kutub Al-Tis 'ah yang terdiri dari Shahih Al-Bukhari, Shahih Muslim, Sunan Abu Daud, Sunan Al-Tirmizi, Sunan Al-Nasa'i, Sunan Ibn Majah, Muwatha' Malik, Sunan Al-Darimi, dan Musnad Ahmad. Adapun teknik pengumpulan data, penulis menggunakan bantuan aplikasi android " Jami' Al-Kutub AlTis'ah" dari lembaga Arabia for Information \& Technology. Hasil dari kajian ini menunjukkan bahwa riba dapat dipetakan dalam dua klasifikasi; riba al-Ba' $i$ dan riba al-Duyun. Katagorisasi riba kedalam dua jenis ini adalah pembagian yang sederhana dan simple. Apabila riba terjadi dalam transaksi jual beli, dinamakan riba riba al-Ba'i. Selanjutnya, jika riba terjadi dalam transasksi hutang piutang, dinamakan riba al-Duyun. Kemudian tidak semua jual beli terjadi riba, dan tidak semua transaksi hutang piutang dianggap riba.
\end{abstract}

Kata Kunci: Riba, Hadis, Ontologi

\begin{abstract}
Abstrack
This article contains a thematic study of Ahkam's hadith on the ontology of riba. This study is included in the library research category. The study method used is descriptive analytical. Primary data in this study came from nine primary hadith books, namely Al-Kutub Al-Tis'ah consisting of Sahih Al-Bukhari, Sahih Muslim, Sunan Abu Daud, Sunan Al-Tirmizi, Sunan AlNasa'I, Sunan Ibn Majah., Muwatha 'Malik, Sunan Al-Darimi, and Musnad Ahmad. As for data collection techniques, the author uses the android application "Jami 'Al-Kutub Al-Tis'ah" from the Arabia for Information \& Technology institute. The results of this study indicate that riba can be mapped into two classifications; riba al-Ba'i and riba of al-Duyun. The categorization of riba into these two types is a simple and simple division. If riba occurs in a buying and selling transaction, it is called riba al-Ba'i. Furthermore, if riba occurs in accounts payable transactions, it is called riba al-Duyun. Then not all buying and selling occurs riba, and not all accounts payable transactions are considered riba.
\end{abstract}

Keywords: Riba, Hadits, Ontology

\section{A. PENDAHULUAN}

Pada masa Rasulululah shalallahu 'alaihi wasallam ada seorang lelaki yang berangkat kerja lewat di depan Nabi shalallahu 'alaihi wasallam. Para sahabat takjub tatkala melihat lelaki tersebut, seorang yang rajin dan semangat bekerja. Para sahabat berkata: "wahai Rasulullah shalallahu 'alaihi wasallam, seandaian lelaki ini berada di jalan Allah ta'ala". Nabi shalallahu 'alaihi wasallam menjawab: "Seandainya lelaki ini 
keluar mencari rezki untuk anaknya yang masih kecil, atau untuk kedua orang tuanya yang sudah tua, atau untuk dirinya sendiri agar terjaga kehormatannya, maka dia berada dijalan Allah ta'ala. Selanjutnya, jika dia keluar bekerja hanya untuk pamer dan sombong, maka dia berada di jalan syaitan". Kisah diatas diceritakan oleh sahabat Kaab bin Ujrah radhiyallahu anhu, sebagaimana dikutip oleh Ath-Thabrani dalam Al-Mu'jam Al-Kabir (Ath-Thabrani, 1994:129).

Dari kisah diatas diketahui bahwa mencari harta bukan sesuatu yang tercela dalam Islam. Sebaliknya, Islam memerintahkan pemeluknya untuk bekerja mencari harta. Bahkan, bekerja mencari harta dalam Islam merupakan salah satu ibadah yang diberi ganjaran pahala. Namun yang berpotensi tercela adalah caranya. Adapun harta itu sendiri bisa terpuji sebagai sarana untuk mendapatkan kemaslahatan dunia dan akhirat. Ibnu Qudamah Al-Maqdisi menyebutkan tiga manfaat harta untuk kemaslahatan akhirat (Al-Maqdisi, 2019: 411-414), yaitu: (1) memberlanjakan harta untuk kepentingan pemilik harta itu sendiri, seperti kebutuhan haji dan umrah, atau kebutuhan sandang dan pangan sebagai penunjang ibadah, (2) memberlanjakan harta kepada orang lain, dalam bentuk sedekah, muruah, wiqayah, dan upah, (3) dan harta yang diberlanjakan untuk sarana penunjang ibadah, seperti membangun mesjid.

Pembahasan tentang harta menjadi sangat penting, sebab manfaat dan kedudukan harta juga penting dalam Islam. Bahkan dalam kajian maqasid syariah, harta merupakan salah satu pembahasan penting. Dan, harta yang dimiliki seseorang sangat terjaga dalam Islam (Al-Juda'I, 1997: 334;). Oleh sebab itu, Islam menetapkan ramburambu yang perlu dijaga oleh seseorang ketika bekerja mencari harta. Agar kerja yang dilakukan bernilai ibadah, rambu-rambu tersebut harus dijaga.
Di antara rambu-rambu yang diatur dalam Alquran, seseorang dilarang mengumpulkan harta dengan cara batil. Allah ta'ala berfirman:

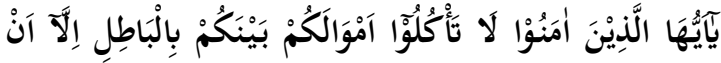

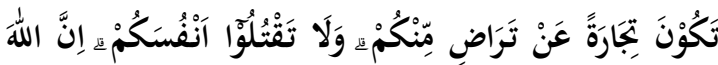
كَانَ بِكُمْ رَحِيْمًا

"Wahai orang-orang yang beriman! Janganlah kamu saling memakan harta sesamamu dengan jalan yang batil (tidak benar), kecuali dalam perdagangan yang berlaku atas dasar suka sama suka di antara kamu. Dan janganlah kamu membunuh dirimu. Sungguh, Allah Maha Penyayang kepadamu" (Q.S.An-Nisa: 29). ${ }^{1}$

Manusia akan terus termotivasi mencari harta, agar eksitensi manusia itu sendiri terjaga. Harta merupakan salah satu kebutuhan primer dalam kehidupan manusia. Oleh sebab itu, syariat telah menetapkan aturan tentang harta. Namun dalam mencari harta, seringkali manusia melanggar ketentuan syariat tersebut. Harta yang diperoleh bukan dengan cara yang dibenarkan syariat (batil) menjadi harta haram. AlUtsaimin menyebutkan ada tiga sebab yang menjadikan harta haram: zalim, gharar, dan riba (Al-Utsaimin, 1421: 120).

Dari ketiga sebab yang diatas, riba salah satu bentuk kebatilan yang sering terjadi. Padahal riba merupakan cara yang sangat batil dalam mengumpulkan harta. Bahkan, Adz-Dzahabi (2017:28) mengkatagorikan riba sebagai salah satu dosa besar. Terdapat banyak ayat dalam Alquran yang melarang riba, diantaranya:

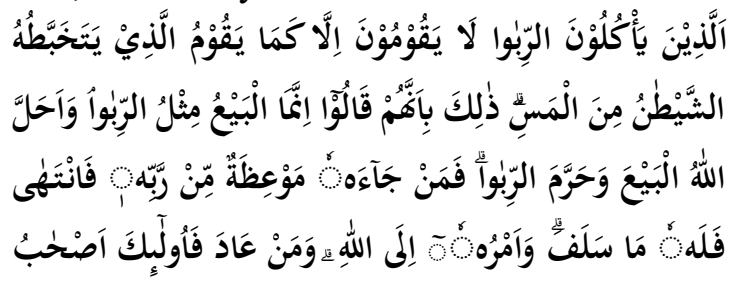

${ }^{1}$ Semua ayat alquran serta terjemahannya diisini diambil dari Qur'an Kemenag In MS. Word yang dikembangkan oleh Lajnah Pentashihan Mushaf Al-Qur'an (LPMQ) (https://lajnah.kemenag.go.id) sebagai satuan kerja di bawah Badan Litbang dan Diklat Kementerian Agama. Program ini dapat diunduh di https://lajnah.kemenag.go.id/unduhan/category/1-qkiw. 


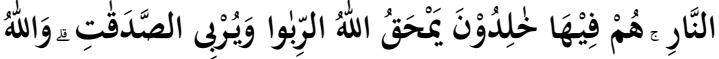<smiles>[AsH2][AsH2]=[AsH2]</smiles>

"Orang-orang yang memakan riba tidak dapat berdiri melainkan seperti berdirinya orang yang kemasukan setan karena gila. Yang demikian itu karena mereka berkata bahwa jual beli sama dengan riba. Padahal Allah telah menghalalkan jual beli dan mengharamkan riba. Barangsiapa mendapat peringatan dari Tuhannya, lalu dia berhenti, maka apa yang telah diperolehnya dahulu menjadi miliknya dan urusannya (terserah) kepada Allah. Barangsiapa mengulangi, maka mereka itu penghuni neraka, mereka kekal di dalamnya. Allah memusnahkan riba dan menyuburkan sedekah. Allah tidak menyukai setiap orang yang tetap dalam kekafiran dan bergelimang dosa" (Q.S.AlBaqarah: 275-276).

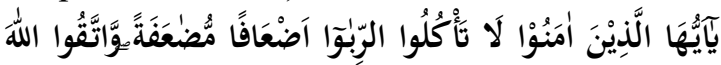

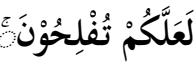

"Wahai orang-orang yang beriman! Janganlah kamu memakan riba dengan berlipat ganda dan bertakwalah kepada Allah agar kamu beruntung” (Q.S.Ali Imran: 131).

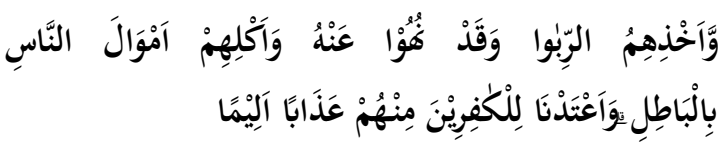

"Dan karena mereka menjalankan riba, padahal sungguh mereka telah dilarang darinya, dan karena mereka memakan harta orang dengan cara tidak sah (batil). Dan Kami sediakan untuk orang-orang kafir di antara mereka azab yang pedih" (Q.S.AnNisa: 161).

Atas dasar beberapa ayat Alquran diatas, para ulama mengatakan riba hukumnya haram. Keharaman riba termasuk

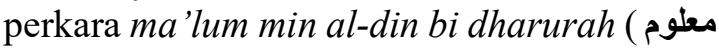
(من الدين بالضرورة , yaitu perkara yang jelas dan terang-bederang hukumnya. Oleh sebab itu, seseorang bisa dianggap kufur jika menghalalkan riba atau tidak mengharamkan riba. Kekufuran tersebut diakibatkan pengingkaran terhadap perkara ma'lum min al-din bi dharurah (Al-Bajuri, 2004:253).
Walaupun banyak ayat Alquran yang berbicara tentang keharaman riba. Namun, Alquran tidak mendefinisikan secara detail tentang hakikat dan klasifikasi riba. Oleh sebab itu, potensi seseorang keliru dalam memahami riba sangat memungkinkan. Bisa saja sesuatu yang bukan riba dianggap sebagai riba, dan begitu juga sebaliknya. Akhirnya, muncul anggapan sebagian masyarakat yang mengatakan: "system ekonomi syariah dan system ekonomi konvensional sama saja. Sama-sama riba". Atau anggapan: "antara bank syariah dan konvensional: beda kosmetik saja". Dan berbagai anggapan keliru lainnya.

Persepsi keliru diatas perlu diluruskan. Dalam kontek ini, Alquran tidak bisa dipahami secara parsial. Artinya, Alquran harus dipahami "satu paket" dengan hadis. Peran hadis sangat penting dalam masalah ini. Sebagaimana yang diketahui hadis merupakan sumber hukum Islam yang disepakati oleh para ushuliyun setelah Alquran. Dan, salah satu fungsi hadis sendiri untuk menjelaskan dan merinci hukum yang ada dalam Alquran. Oleh sebab itu, untuk memahami, mendefinisi, dan mengklasifikasi riba secara detail, kajian terhadap hadis-hadis tentang riba sangat diperlukan.

Berdasarkan latar belakang diatas, penulis ingin mengkaji dan menganalisa masalah ini lebih dalam. Untuk membatasi tema kajian, kajian ini hanya akan mengkaji tentang ontologi riba dalam hadis. Kajian ini dengan mengangkat judul jurnal yaitu: "Ontologi Riba dalam Hadist (Kajian Tematik Hadis Ahkam)”.

\section{B. METODE PENELITIAN}

Penelitian ini termasuk katagori penelitian kepustakaan (library research), sebab data yang diteliti bersumber dari naskah atau buku dari khazanah kepustakaan. Selain referensi yang sudah tercetak, karya-karya non cetak yang yang tersimpan dalam media elektronik juga dijadikan sumber data dalam penelitian kepustakaan ini (Harahap, 2014: 68-74; Nazir, 1985: 25; Khatibah, 2011: 3639). 
Adapun teknik pengumpulan data, penulis menggunakan bantuan aplikasi android “Jami' Al-Kutub Al-Tis'ah” ( جامع dari lembaga Arabia for Information \& Technology. Melalui apalikasi android ini, penulis akan mencari data yang relevan dengan penelitian ini dari sembilan kitab hadis yang dikenal dengan istilah $\mathrm{Al}$ Kutub Al-Tis'ah. Al-Kutub Al-Tis'ah terdiri dari Shahih Al-Bukhari, Shahih Muslim, Sunan Abu Daud, Sunan Al-Tirmizi, Sunan Al-Nasa'I, Sunan Ibn Majah, Muwatha' Malik, Sunan Al-Darimi, dan Musnad Ahmad. Dikarenakan semua hadis yang digunakan dalam kajian ini menggunakan aplikasi “Jami' Al-Kutub Al-Tis'ah", penulis tidak menyebutkan referensi kitab hadis secara detail (penerbit, cetakan, tahun, dll). Penulis hanya menyebutkan nama kitab dan nomor hadis sesuai hasil pencarian menggunakan aplikasi “Jami' Al-Kutub Al-Tis'ah".

Selain data primer dari Al-Kutub AlTis'ah, penulis juga menggunakan data sekunder sebagai penunjang. Data penunjang ini berasal dari referensi-referensi yang berkaitan dengan tema bahasan, terutama literatur fiqh. Adapun metode penelitian yang digunakan adalah metode deskriftif analitis atau disebut metode analitis kritis (Suriasumantri, 1998: 41-61). Adapun langkah-langkahnya adalah sebagai berikut:

1. Mengumpulkan data-data dari berbagai sumber, baik sumber primer maupun sekunder yang terkait dengan tema penelitian.

2. Melakukan identifikasi wacana terkait judul dan masalah penelitian dari sumber primer maupun sekunder.

3. Membaca, menelaah, menganalisis, dan mengintepretasi data penelitian yang sudah dikumpulkan terkait dengan teman penelitian serta melakukan pencocokan dan perbandingan antara berbagai data yang ada.

\section{PEMBAHASAN}

Hadis-hadis tentang riba sangat banyak. Sesuai dengan latar belakang diatas, kajian dalam artikel ini akan dipersempit pada pembahasan "Ontologi Riba". Ontologi merupakan salah satu kajian filsafat ilmu. Merujuk kepada Ahmad Tafsir (2013:22), istilah ontologi istilah yang digunakan membicarakan hakikat dan struktur sesuatu. Istilah ontology riba dalam kajian ini terbagi kedalam dua pembahasan; hakikat dan struktur riba. Hakikat riba untuk menjawab pertanyaan apa riba itu sebenarnya. Adapun struktur riba untuk menjelaskan cabangcabang riba atau klasifikasi riba.

Hasil penelusuran penulis menunjukkan hadis-hadis tentang tema kajian masih sangat banyak. Oleh sebab itu, penulis melakukan analisis terhadap redaksi teks, substansi, dan jalur periwayatan. Hasil analisi penulis menunjukkan bahwa kebanyakan hadis-hadis tersebut memiliki substansi yang sama. Namun redaksi dan jalur periwayatan yang sering tejadi perbedaan. Tahap selanjutnya, penulis melakukan pemetaan untuk memilih hadis-hadis yang paling relevan dengan tema kajian. Dan penulis dalam kajian ini hanya menyebutkan satu referensi kitab hadis untuk tiap hadis, walaupun substansi hadis tersebut terdapat dalam beberapa riwayat dalam beberapa referensi. Tujuanya agar mempersingkat pembahasan redaksional, dan fokus pada substansi.

Adapun untuk memastikan faliditas hadis, penulis mendahulukan hadis-hadis riwayat Bukhari dan Muslim dari selain mereka berdua. Penulis baru menggunakan riwayat selain Bukhari dan Muslim, apabila tidak didapati riwayat terkait substansi dalam riwayat mereka berdua. Selain itu, untuk menyingkat pembahasan, penulis akan menerjemahkan hadis tanpa keseluruhan jalur periwayat (sanad). Dalam penerjemahan, penulis langsung menerjemahkan ke perawi dari kalangan sahabat. Adapun teks arab, maka akan dimuat secara utuh.

Berikut ini adalah hadis-hadis yang paling relevan dan menjadi core issue dalam kajian ini.

Hadis Pertama (hadis Ubadah bin Shamit):

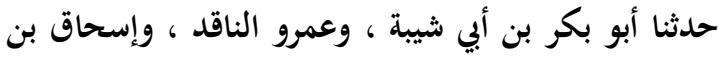
إبراهيم - واللفظ لابن أبي شيبة - قال إسحاق : أخبرنا، 
Edy Saputra, Ontologi Riba Dalam Hadis...

وقال الآخران : حدثنا وكيع ، حدثنا سفيان ، عن خالد

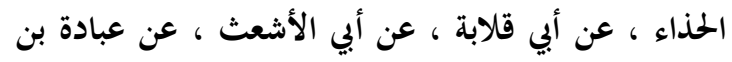

الصامت ، قال : قال رسول الله صلى الله عليه وسلم : " الذهب بالذهب، والفضة بالفضة، والبر بالبر، والشعير بالثعير، والتمر بالثمر، والملح بالملح مثلا بمثل سواء بسواء

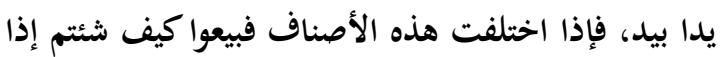
كان يدا بيد

"Dari Ubadah bin Shamit radhiyallahu 'anhu berkata, Rasulullah shallahu 'alaihi wasallam bersabda: Jika terjadi jual beli emas dengan emas, perak dengan perak, bur (gandum kasar) dengan bur, syair (gandum kasar) dengan syair, kurma dengan kurma, atau garam dengan haram, maka jumlah (takaran atau timbangan) kedua jenis barang tersebut harus sama dan dilakukan secara tunai (kontan). Namun jika jual beli terjadi pada komoditi yang berbeda, silahkan dilakukan sesukamu (tidak ada ketentuan jumlah) selamu masih kontan" (Shahih Muslim, no. 1587).

Hadis kedua (hadis Abu Bakrah):

حدثنا صدقة بن الفضل ، أخبرنا إسماعيل ابن علية ، قال :

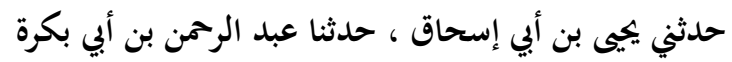

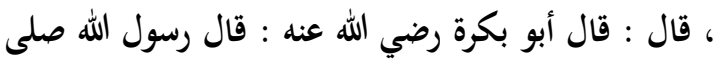
الله عليه وسلم : " لا تبيعوا الذهب بالذهب إلا سواء بسواء، والفضة بالفضة إلا سواء بسواء، وبيعوا الذهب بالفضة، والفضة بالذهب كيف شئت بـ

"Abu Bakrah radhiyallahu 'anhu berkata, Rasulullah shallahu 'alaihi wasallam bersabda: Jangan kalian menjual emas dengan emas atau perak dengan perak, kecuali dengan jumlah (takaran atau timbangan) kedua jenis barang tersebut harus sama. Adapun jika menjual emas dengan perak atau perak dengan emas, silahkan lakukan sesukamu (tidak ada ketentuan jumlah)" (Shahih Bukhari, no. 2175).

Hadis ketiga (hadis Abu Hurairah):
حدثنا قتيبة ، عن مالك ، عن عبد الجيد بن سهيل بن عبد الرحمن ، عن سعيد بن المسيب ، عن أبي سعيد الحدري ،

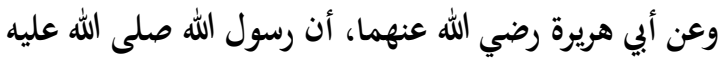
وسلم استعمل رجلا على خيبر، فجاءه بتمر جنيب ، فقال

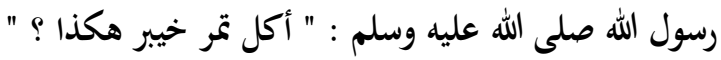

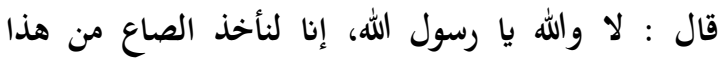
بالصاعين، والصاعين بالثلاثة. فقال رسول الله صلى الله عليه وسلم : " لا تفعل، بع الجمع بالدراهم، ثم ابتع بالدراهم جنيبا

"Abu Said Al-Khudri dan Abu Hurairah radhiyallahu 'anhuma bercerita, sesungguhnya Rasulullah shallahu 'alaihi wasallam mempekerjakan seorang lelaki untuk mengurus tanah Khaibar. Kemudian lelaki tersebut menghadap Rasulullah shallahu 'alaihi wasallam dengan membawa kurma Janib (kurma khaibar yang berkualitas tinggi). Lalu Rasulullah shallahu 'alaihi wasallam bertanya: Apakah semua kurma Khaibar seperti ini kualitasnya? Lelaki ini menjawab: Tidak wahai Rasulullah. Biasanya kami menukar (jual beli) satu sha' kurma Janib dengan dua sha' kurma biasa. Atau dua sha' kurma Janib dengan tiga sha' kurma biasa. Kemudian Rasulullah shallahu 'alaihi wasallam bersabda: Jangan lakukan yang demikian, juallah beberapa sha' kurma biasa dengan beberapa dirham, selanjutnya belilah kurma Janib itu dengan dirham hasil penjualan kurma Janib" (Shahih Bukhari, no. 2202).

Hadis keempat (hadis Anas bin Malik):

حدثنا هشام بن عمار ، قال : حدثنا إسماعيل بن عياش ،

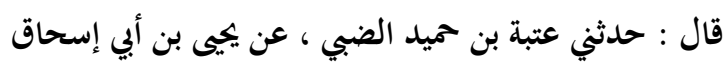

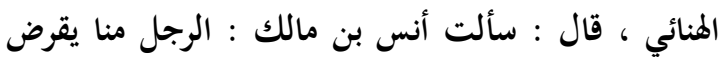
أخاه المال فيهدي له ؟ قال : قال رسول الله صلى الله عليه

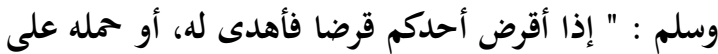

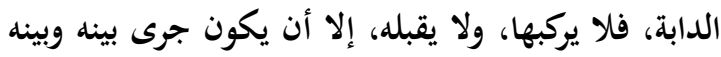
قبل ذلك." - ملهابه 
"Yahya bin Abi Ishaq Al-Hunaiy pernah bertanya kepada Anas bin Malik: Bolehkah seseorang dikalangan kami yang berhutang kepada saudaranya, kemudian dia memberi hadiah kepadanya? Anas bin Malik menjawab, Rasulullah bersabda: "Jika seseorang di antara kalian memberikan hutang kepada seseorang, lalu orang yang berhutang memberikan hadiah kepadanya atau memboncengnya diatas hewan tunggangan (kendaraan), janganlah mau dibonceng dan jangan terima hadiahnya, kecuali jika hal itu memang sudah biasa terjadi di antara mereka" (Sunan Ibnu Majah, no 2432)

Hadis kelima (hadis Abu Rafi'):

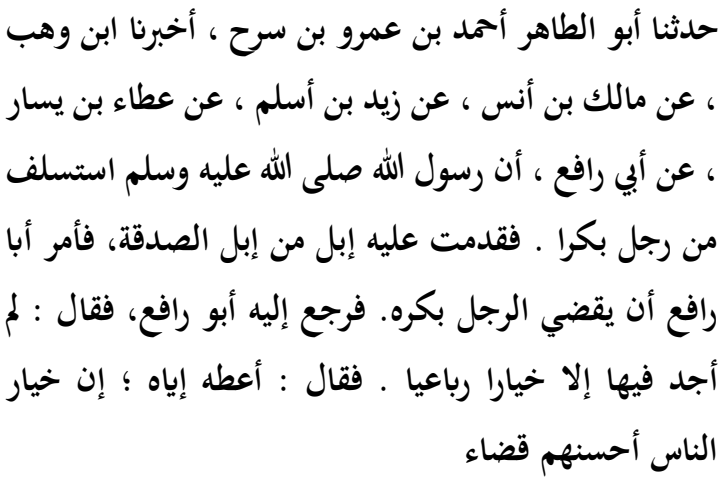

"Abu Rafi' bercerita, sesungguhnya Rasulullah shallahu 'alaihi wasallam pernah meminjam seekor onta yang masih muda kepada seseorang. Kemudian aku membawaa seekor onta sedekah kepada beliau. Selanjunya, Rasulullah shallahu 'alaihi wasallam memerintahkan Abu Rafi' untuk membayar hutang onta muda kepada pemberi hutang. Abu Rafi' pulang mejumpai rasulullah shallahu 'alaihi wasallam seraya berkata: aku tidak mendapati kecuali onta yang sudah berumur tujuh tahun. Rasulullah shallahu 'alaihi wasallam bersabda: berikan saja onta tersebut kepadanya. Sesungguhnya manusia terbaik adalah yang paling bagus membayar hutangnya" (Shahih Muslim, no. 1600).

Hadis keenam (hadis Jabir bin Abdullah):
عن جابر بن عبد الله ، قال : أتيت البي صلى الله عليه

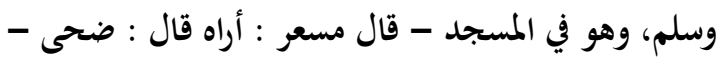
فقال : " صل ركعتين ". وكان لي عليه دين فقضاني وزادين "Jabir bin Abdullah berkata, aku menjumpai Rasulullah shallahu 'alaihi wasallam di mesjid. Mis'ar bekata: aku berpendapat Jabir mengatakan saat waktu Dhuha. Lalu Rasulullah shallahu 'alaihi wasallambersabda: shalatlah dua rakaat. Rasulullah shallahu 'alaihi wasallam memiliki hutang kepadaku. Maka beliau membayar hutang serta memberikan tambahan kepadaku" (Shahih Bukhari, no. 443).

Dari substansi enam hadis diatas, riba dapat dipetakan kedalam dua klasifikasi; riba $a l-B a$ ' $i$ dan riba al-Duyun. Katagorisasi riba kedalam dua jenis ini adalah pembagian yang sederhana dan simple. Walaupun para ulama berbeda dalam mengelompokkan riba, namun perbedaan itu hanya perbedaan istilah bukan substansi. Oleh sebab itu, katagorisasi riba kedalam dua jenis yang penulis sebutkan telah memuat semua substansi katagorisasi para ulama dan sesuai dengan kaidah fiqih:

العبرة في التصرفات للمقاصد والمعاني لا للألفاظ والمباني "Standar dalam transaksi adalah substansi, bukan istilah" (Zarqa, 1996:55).

Apabila riba yang terjadi dalam transaksi jual beli, dinamakan riba riba al$B a^{\prime} i$ (hadis pertama, kedua, dan ketiga). Selanjutnya, jika riba yang terjadi dalam transasksi hutang piutang, dinamakan riba alDuyun (hadis keempat, kelima, dan keenam). Kemudian tidak semua jual beli terjadi riba, dan tidak semua transaksi hutang piutang dianggap riba. Kedua klasifikasi riba tersebut, baik dalam jual beli atau hutang, akan dirinci dibawah ini.

\section{Riba Jual Beli (ربا البيوع)}

Riba tidak terjadi dalam semua transaksi jual beli. Riba dalam transaksi jual beli hanya terjadi pada komoditi tertentu. Dalam hadis pertama dan kedua, Rasulullah menyebutkan beberapa komoditi ribawi, yaitu: emas, perak, gandum kasar (bur), gandum halus (syair), kurma, dan garam. Para 
ulama sepakat atas haramnya riba pada enam komoditi ini secara fadhal dan nasi'ah (AlButy, 2011:41).

Selain memuat daftar komoditi ribawi, tiga hadis diatas juga menjelaskan secara detail aturan jual beli enam komoditi ribawi dan komoditi lainnya yang sama illat nya. Agar jual beli komoditi ribawi tidak ada unsur riba, maka aturan tersebut mesti dipenuhi dalam transaksi jual beli komoditi ribawi. Dalam hadis pertama disebutkan: “...maka jumlah (takaran atau timbangan) kedua jenis barang tersebut harus sama dan dilakukan secara tunai (kontan). Namun jika jual beli terjadi pada komediti yang berbeda, silahkan dilakukan sesukamu (tidak ada ketentuan jumlah) selama masih kontan". Jadi hadis ini memuat dua aturan pokok:

1) Apabila transaksi jual beli komoditi ribawi yang sejenis dan sama illat nya, seperti emas dengan emas atau gandum dengan gandum, maka harus memenuhi dua aturan. Pertama, kedua komoditi مثلا بمثل Tersebut harus sama jumlahnya سواء بسواء). Kedua, serah terima kedua komoditi tersebut harus kontan / cash dan tidak boleh diakhirkan serah terima salah satu atau keduanya (يدا بيد).

2) Apabila terjadi transaksi jual beli komoditi ribawi yang berbeda jenis tetapi sama illat nya, seperti emas dengan perak atau gandum dengan kurma, maka cukup memenuhi satu aturan saja, yaitu kontan / cash (يدا بيد). Tidak disyaratkan dengan jumlah yang sama.

Apabila dua aturan diatas tidak terpenuhi dalam jual beli komoditi ribawi, maka transaksi tersebut mengandung unsur riba. Apabila tidak sama jumlah / volume pada jual beli yang mensyaratkan jumlah, dinamakan riba fadhal (ربا الفضل). Dan apabila dilakukan secara tidak kontan, dinamakan riba nasi'ah (ربا النسيئة). Dalam jual beli komoditi ribawi yang sejenis dan sama illat nya, perbedaan kualitas tidak berpengaruh. Hal ini sesuai dengan substansi hadis yang ketiga. Dalam hadis yang ketiga, Nabi melarang penukaran satu sha' kurma Janib (kurma Khaibar dengan kualiatas terbaik) dengan dua sha' kurma lain. Larangan tersebut untuk menghidari riba, karena keduanya sejenis yaitu kurma dan sama llat nya. Walaupun kedua tersebut memiliki kualitas yang berbeda.

Selanjutnya muncul pertanyaan, apakah komoditi riba hanya terbatas pada enam komoditi saja? Dalam menjawab pertanyaan ini, para ulama berbeda pendapat. Perbedaan pendapat ini didasari atas perbedaan pandangan dalam menentukan illat pada enam komoditi yang disebutkan dalam hadis pertama dan kedua. Dalam masalah ini ada beberapa pendapat para ahli (Al-Buty, 2011:41-56; Yunus, 2001: 213, 307; Idris, 2000: 5-8):

1) Riba hanya terjadi pada enam komoditi diatas. Selain dari itu, riba tidak terjadi dalam jual beli. Ini adalah pendapat mazhab Zahiriyah dan Syiah. Pembatasan riba hanya pada enam komoditi ini didasari pada penolakan Qiyas sebagai sumber hukum dalam mazhab Zahiriyah. Atas dasar pendapat ini, maka jual beli apapun selain enam komoditi yang disebutkan dalam hadis, tidak perlu mengikuti dua aturan diatas, termasuk jual beli mata uang dalam konten muamalah modern.

2) Mazhab Hanafi berpandangan bahwa illat barang enam komoditi diatas ada dua. Timbangan yang terjadi pada emas atau perak dan takaran yang terjadi pada empat komoditas lainnya. Atas dasar itu, semua transaksi barang yang bisa ditimbang dan ditakar mesti memenuhi dua aturan diatas.

3) Mazhab Maliki menetapkan dua illat pada enam komoditi diatas. Standar harga (Al-Asman) pada emas dan perak dan makanan pokok yang dapat disimpan lama (Al-Iktuyat wa Al-Iddikhar) pada gandum, kurma, dan garam.

4) Mazhab Syafi'i juga menetapkan dua llat. Sama seperti mazhab maliki, Standar harga (Al-Asman) pada emas dan perak. Adapun pada empat komoditi lainnya illatnya makanan (Al-Ta'mu). Atas dasar pendapat mazhab Syafi'I dan mazhab Maliki, uang yang berlaku hari ini 
dengan berbagai nama mata uang yang berbeda-beda di berbagai negara, termasuk barang riba karena dijadikan Al-Saman layaknya emas dan perak pada masa Nabi. Jadi, jual beli atau tukar menukar uang mesti memenuhi dua syarat diatas. Apabila sejenis, seperti rupiah dengan rupiah, maka harus sama nominal keduanya dan cash. Apabila berbeda jenis, seperti rupiah dengan dolar, cukup memenuhi syarat kontan serah terima keduanya, tidak perlu sama nominal keduanya. Seperti halnya uang, beras sebagai makanan pokok hari juga termasuk barang ribawi.

5) Ada tiga riwayat dari Imam Ahmad dalam mazhab Hanbali. Riwayat yang paling masyhur sama seperti mazhab Hanafi. Timbangan pada emas dan perak, takaran pada empat komoditi lainnya.

\section{Riba Hutang (ربا الديون)}

Dalam Islam, setidaknya ada dua jenis akad; akad social (Tabarru') akad bisnis (Tijarah). Kedua akad tersebut memiliki orientasi yang berbeda. Orientasi akad bisnis (Tijarah) adalah keuntungan dalam bentuk materi atau harta yang diharapkan. Sedangkan akad akad social (Tabarru') hanya sekedar membantu, tidak mengharapkan keuntungan materi atau harta.

Hutang piutang adalah akad sosial (Tabarru'), bukan akad bisnis (Tijarah). Tujuan akad social adalah membantu, bukan mencari keuntungan. Jika seorang pemberi hutang ingin mengambil keuntangan dari hutang, jangan memberi hutang. Pemberi hutang bisa memilih akad bisnis dengan beberapa skema akad syirkah, seperti mudharabah atau murabahah misalnya. Disinilah letak perbedaan antara bank syariah dengan bank kovensional. Skema akad di bank syariah adalah jual beli atau akad bisnis, maka keuntungannya halal. Adapun bank konvensional melakukan akad hutang atau pinjaman berbunga, untung dari akad ini haram karena riba (Sahroni, 2019:155-157).

Riba dalam hutang piutang ada dua bentuk, yaitu persyaratan manfaat dan denda keterlambatan. Namun, dalam hadis-hadis
Nabi hasil penelusuran penulis, hanya memuat satu jenis riba yang terkait hutang, yaitu persyaratan manfaat dari hutang. Dalam hadis keempat yang menjadi objek kajian secara tegas tidak membenarkan ada persyaratan manfaat yang akan diperoleh dari hutang piutang. Manfaat yang dimaksud disini tidak dibatasi dalam satu bentuk, tetapi dalam berbagai bentuk. Bisa manfaat dalam bentuk uang (bunga), juga manfaat dalam bentuk jasa (al-Maqdisi, 1985: 36).

Dalam hadis keempat, manfaat dicontohkan seperti pemberian hadiah atau tumpangan kendaraan. Pemberian hadiah atau tumbangan yang disebabkan oleh hutang, ini sudah termasuk riba. Pemberi hutang akan menerima bayaran hutang sesuai yang dihutangkannya serta tambahan manfaat dalam bentuk hadiah atau tumpangan. Adapun jika pemberian hadiah atau tumbangan sudah terbiasa sebelum terjadi hutang piutang, dan pemberian hadiah atau tumpangan bukan karena sebab hutang, maka ini tidak dipermasalahkan. Kebolehan ini sesuai dengan akhir hadis keempat: “ "إلا أن يكون "جرى بينه وبينه قبل ذلك

Demikian juga jika tambahan manfaat diberikan diakhir pembayaran hutang. Dan tidak dijadikan syarat diawal akad, ini tidak dipermasalahkan dan bukan bagian dari riba (Adh-Dharir, 2003: 65). Bahkan dianggap sebagai husn al-Qadha (pelunasan yang baik). Dalam hadis kelima, pembayaran hutang Nabi oleh Abu Rafi' dengan jumlah yang lebih banyak. Abu Rafi' membayar hutang dengan onta yang lebih besar dan tua, padahal onta yang dihutangkan lebih kecil. Ini menunjukkan ada perbedaan jumlah daging dan berat kedua onta tersebut. Namun, hal ini tidak dipermasalahkan. Bahkan, ini dianggap perbuatan terpuji dan Nabi mengangap sebagai manusia yang terbaik dalam hadis kelima: “"إن خيار الناس أحسنهم قضاء”. Demikian juga Nabi membayar hutang kepada Jabir bin Abdullah dengan melebihkan pembayaran dari apa yang beliau pinjam (hadis keenam)

Selanjutnya, dalam kajian terhadap hadis-hadis riba dari sumber data rujukan penelitian ini, penulis tidak menemukan 
hadis yang membicarakan jenis atau bentuk riba yang kedua dalam hutang piutang. Namun riba ini yang menjadi objek utama didalam Alquran, yaitu riba dalam bentuk denda keterlambatan dalam membayar hutang. Denda keterlambatan dalam membayar hutang disebut dengan istilah riba Jahiliyah (ربا الجاهلية) (Karim dan Sahroni, 2018:3-4; Yunus, 2001:203,307; Idris, 2000: 5-8). Orang Jahiliyah dahulu, apabila jatuh tempo pembayar hutang, pemberi hutang mengatakan: "bayar sekarang atau diribakan?", atau orang yang berhutang berkata:"tambahkan waktu, maka aku tambahkan nilai hutang". Riba Jahiliyah ini yang dimaksud oleh semua ayat Alquran yang berbicara tentang riba. Keharaman riba ini merupakan kesepakatan para ulama (Al-Buty, 2011:40).

\section{KESIMPULAN}

Riba merupakan salah satu dosa besar. Para ulama telah sepakat akan keharaman riba. Dari penjelasan enam hadis diatas, riba dapat dipetakan kedalam dua klasifikasi; riba al-Ba'i dan riba al-Duyun. Katagorisasi riba kedalam dua jenis ini adalah pembagian yang sederhana dan simple.

Riba al-Ba'i adalah riba yang terjadi dalam transaksi jual beli. Riba tidak terjadi dalam semua transaksi jual beli. Riba dalam transaksi jual beli hanya terjadi pada komoditi ribawi. Ada aturan jual beli komoditi ribawi yang harus dipenuhi dalam transaksi jual beli. Pertama, apabila transaksi jual beli komoditi ribawi yang sejenis dan sama illat nya, maka harus memenuhi dua aturan. Pertama, kedua komoditi tersebut harus sama jumlahnya dan serah terima kedua komoditi tersebut harus kontan / cash dan tidak boleh diakhirkan serah terima salah satu atau keduanya. Kedua, apabila terjadi transaksi jual beli komoditi ribawi yang berbeda jenis tetapi sama illat nya, maka cukup memenuhi satu aturan saja, yaitu kontan dan tidak disyaratkan dengan jumlah yang sama.

Riba al-Duyun adalah riba yang terjadi dalam transaksi hutang piutang. Namun, tidak semua hutang piutang terjadi riba. Dalam hutang piutang terjadi riba dalam dua bentuk. Bentuk pertama, apabila ada persyaratan manfaat yang akan diambil oleh pemberi hutang. Bentuk kedua, ada denda akibat keterlambatan yang dibebankan kepada orang yang berhutang.

\section{DAFTAR PUSTAKA}

Al-Maqdisi, Ibnu Qudamah. (2019). Mukhtasar Minhaj Al-Qasidin. Riyadh: Maktabah Dar Al-Hijrah.

Al-Maqdisi, Ibnu Qudamah. (1985). AlMughni. Cet.I. jilid ke-4. Beirut: Dar al-Fikri.

At-Thabrani, Sulaiman bin Ahmad. (1994). Jilid ke-19. Kairo: maktabah Ibnu Taimiyah.

Al-Buty, Muhammad Said Ramadhan. (2011). Muhazarat fi Al-Fiqh alMuqaran. Damaskus: Dar Al-Fikr.

Ahmad Tafsir. 2013. Filsafat ilmu. Cet. 7. Bandung: Remaja Rosdakarya.

Adz-Dzahabi, Syamsuddin. 2017. Alkabair. Depok: Maktabah At-Turmusi.

Al-Juda'I, Abdullah Yusuf. (1997). Taisir Ilmi Ushul Al-Fiqh. Bairut: Muassasah Al-Rayyan.

Adh-Dharir, Shiddiq. (2003). Al-Jawaiz wa al-hawafiz 'ala 'Anwa' al-Hisabat almasrafiyah. Hauliyatul barakah. Edisi V, oktober 2003.

Al-Bajury, Ibrahim. 2004. Tuhfatu Murid Syarh Jauhar Tauhit. Bairut:Dar AlKutub Al-Islamiyah.

Al-Utsaimin, Muhammad Shaleh. (1421). Syarhul Mumti'. Riyadh: dar Ibnu Jauzi.

Harahap, Nursapia. (2014). Penelitian Kepustakaan. Jurnal Iqra' Vol. 08, No. 01, 68-74. 
Idris, Abdul Fattah. (2003). Muamalah alBunuk min Madhar al-Islami. Cet.1. Kairo.

Karim, A.Adiwarman dan Oni Sahroni. (2018). Depok: PT.Raja Grafindo Persada.

Khatibah. (2011). Penelitian Kepustakaan. Jurnal Iqra' Vol.05, no.01, 36-39.

Nazir, Muhammad. (1985). Metode Penelitian. Jakarta: Ghalia Indonesia.

Suriasumantri, Jujun. (1998). Penelitian Ilmiah, Kefilsafatan, dan Keagamaan:
Mencari Paradigma Kebersamaan. In D. \&. Ridwan, Tradisi Baru Penelitian Agama Islam: Tinjauan Antardisiplin Ilmu (p. 41). Bandung: Nuansa.

Sahroni, Oni. (2019). Fikih Muamalah Kontemporer. Jakarta: Republika.

Yunus, Raffiq. (2001). Al-Jami' fi Ushul Riba. Damaskus: dar al-Qalam.

Zarqa, Muhammad. (1996). Syarah alQawaid al-Fiqhiyah. Cet. IV. Damaskus: Dar al-Qalam. 